\title{
UPAYA PENGEMBANGAN KARAKTER ANAK \\ MELALUI MODEL PEMBELAJARAN EXPERIENTIAL LEARNING \\ (Efforts In Developing A Child's Character \\ Through An Experiential Learning Approach Model)
}

\section{Wahyuni Christiany Martono}

Program Studi PG PAUD FKIP Universitas Palangka Raya Jl. H. Timang Komplek Kampus Tunjung Nyaho Palangka Raya

Email : : Wahyuni@fkip.upr.ac.id

\begin{abstract}
The aim of this study was to describe the efforts undertaken to develop children's character through an Experiential Learning model approach at Homy School in Palangka Raya, Central Kalimantan. This study used qualitative method. The subjects of this study were educators, children and the principals. The methodology used was collecting data by observation, interviews and documentation. The technique used to analyze data was a qualitative descriptive technique. The results showed that the implementation of Experiential Learning approach model at Homy School in Palangka Raya Central Borneo could develop children's character. Homy School implements the four stages of Experiential Learning, which are 1) concrete experiences, 2) reflective observation, 3) abstract concepts, and 4) active experiments; all these efforts are focused towards the process of developing a child's character. Positive character outputs of Experiential Learning are: a child feels they are important and able to relate themselves, to friends and the environment. They also becomes more spiritual, likeable, honest, have a sense of love, empathy, independence, responsibility, creativity, active, confident, and enjoy learning. In an effort to develop a child's character through an Experiential Learning approach model at Homy School in Palangka Raya, Central Kalimantan, it was recommended that consistency and good collaboration continue to be maintained between the school (tutors) and parents. In addition, hoped that routine evaluations in every activity carried out.
\end{abstract}

Keywords: Character Development, Experiential Learning Model Approach, Homy School Palangka Raya 


\begin{abstract}
ABSTRAK
Tujuan penelitian ini adalah untuk mendeskripsikan upaya pengembangan karakter anak melalui model pembelajaran Experiential Learning di Homy School Palangka Raya Kalimantan Tengah. Penelitian ini menggunakan pendekatan kualitatif. Subjek dari penelitian ini yaitu pendidik, anak dan kepala sekolah. Metode pengumpulan data dengan observasi, wawancara dan dokumentasi. Teknik yang digunakan untuk menganalisis data menggunakan teknik deskriptif kualitatif. Hasil penelitian menunjukkan bahwa pelaksanaan model pembelajaran Experiential Learning di Homy School Palangka Raya dapat mengembangkan karakter anak. Adapun keempat tahapan Experiential Learning, yaitu tahapan pengalaman konkrit, tahapan observasi refleksi, tahapan berpikir abstrak, dan tahapan pengalaman aktif diterapkan dalam proses pengembangan karakter anak. Karakter positif yang berkembang antara lain: anak menjadi lebih peduli dan menghargai dirinya sendiri, teman serta lingkungannya, religius, toleransi, jujur, memiliki rasa cinta kasih, empati, mandiri, bertanggungjawab, kreatif, aktif, percaya diri, dan gemar belajar. Dalam upaya pengembangan karakter anak melalui model pembelajaran Experiential Learning di Homy School Palangka Raya Kalimantan Tengah, disarankan agar terus terjaga konsistensi dan kolaborasi yang baik antara pihak sekolah (tutor) dan orang tua. Selain itu, diharapkan tidak melupakan evaluasi rutin dalam setiap kegiatan yang dilakukan.
\end{abstract}

\title{
Kata Kunci: Pengembangan Karakter, Model Pembelajaran Experiential Learning, Homy School Palangka Raya
}

\section{PENDAHULUAN}

Kini kita memasuki era Revolusi Industri 4.0, dimana ditandai dengan penggunaan teknologi internet yang mendominasi dalam semua dimensi kehidupan, termasuk dunia pendidikan. Istilah "Milenial" juga sering digunakan dalam merepresentasikan generasi yang hidup di era ini. Generasi Milenial menjalani kehidupan berdampingan dengan seperangkat teknologi cyber dengan kecanggihan yang sangat luar biasa beberapa tahun terakhir ini. Hampir rata-rata kebanyakan remaja dan anak usia sekolah dasar telah memiliki gawai pribadi atau pun dipinjamkan oleh orang tua mereka. Bahkan anak kecil sejak bayi sekali pun sudah banyak yang terpapar dengan gawai, baik itu HP Smartphone atau komputer tablet dengan sistem operasi berbasis android, ios atau windows. Tentunya bukan pemandangan yang asing jika di tempat umum kita melihat mulai dari orang dewasa hingga anak-anak sibuk mengutakatik ponsel pintarnya mulai dari bermain permainan baik online atau offline, media 
sosial, kamera foto atau "chating-an. Mereka terlihat sibuk dengan gawai masingmasing sehingga hampir tidak terlihat komunikasi secara langsung diantara mereka.

Kecanggihan teknologi yang ada di era ini memang sangat membantu semua aspek kehidupan karena membuat banyak hal menjadi lebih mudah. Namun demikian, tidak semua kecanggihan dan kemudahan teknologi di era ini berdampak positif. Di era ini pula mulai dikenal istilah cyber bullying dimana perilaku bullying yang dilakukan pelakunya melalui sarana elektronik seperti media sosial (misalnya: whatsapp, Line, Instagram, Facebook, dan lain-lain). Selain itu, anak-anak menjadi lebih banyak menghabiskan waktu menonton TV ketimbang melakukan hal lainnya (seperti belajar dan olah raga); anak kehilangan kemampuan berbaur dengan masyarakat dan cenderung nyaman dengan kehidupan online; kejahatan di internet, pornografi, perjudian, penipuan, tayangan kekerasan (Ratnaya, 2011).

Dengan melihat betapa besarnya tantangan dunia pendidikan di era Revolusi Industri 4.0 ini maka sangat diperlukan pengembangan karakter anak. Karakter atau watak adalah sifat batin yang mempengaruhi segenap pikiran, perilaku, budi pekerti, dan tabiat yang dimiliki manusia atau mahluk hidup lainnya (Wikipedia, https://id.wikipedia.org/wiki/Karakter, 2019). Masyarakat membentuk karakter melalui pendidik dan orang tua agar anak bersedia bertingkah laku seperti yang dikehendaki masyarakat (Alwisol dalam Arismantoro, 2008). Salah satu strategi yang dapat dilakukan pendidik untuk mengembangkan Pendidikan karakter anak adalah menerapkan metode pembelajaran yang melibatkan partisipasi aktif anak, yaitu metode yang dapat meningkatkan motivasi anak karena seluruh dimensi manusia terlibat secara aktif dengan diberi materi pembelajaran yang konkrit, bermakna, serta relevan dalam kehidupannya (Musfiroh dalam Arismantoro, 2008).

Konsep pembelajaran yang holistik integratif dimana pendidikan berpusat pada anak (child centered) terdapat di sekolah alternatif pertama di Palangka Raya Kalimantan Tengah "Homy School” yang memiliki visi menyelenggarakan pendidikan Holistik-Integratif bagi anak agar memiliki wawasan global dengan tetap memiliki kearifan lokal dengan berlandaskan Kasih Kristus. Dalam model pembelajarannya, Homy School mengadaptasi metode experiential learning. Experiential Learning Theory (ELT) yang dikembangkan oleh David Kolb sekitar awal tahun 1980-an, yang menekankan pada sebuah model pembelajaran yang holistik dalam proses belajar. 
Dalam experiential learning, pengalaman mempunyai peran sentral dalam proses belajar. Dalam teori experiential learning, belajar merupakan proses dimana pengetahuan diciptakan melalui transformasi pengalaman (experience). Experiential learning secara harfiah berarti belajar dari aktifitas mengalami dan merefleksikan apa yang telah dipelajari. Eksperiensial bukan sekedar mendengarkan tetapi lebih pada mensimulasikan situasi kehidupan nyata, misalnya field trip, bermain peran, outbound dan berpartisipasi dalam permainan maupun pengalaman keseharian. Dalam experiential learning melibatkan tubuh, pikiran, perasaan, dan tindakan. Oleh karena itu merupakan pengalaman belajar pribadi yang utuh (Kolb, 2014)

Menurut David Kolb (2014: 32), Experiential Learning step are 1) concrete experience, 2) observation and reflections, 3) formations of abstract concept and generalizations, and 4) testing implementations. Ada dua bentuk model pemahaman pengalaman, yaitu pengalaman nyata (concrete experience) dan konsep abstrak (abstract conceptualization). Selain itu ada pula dua bentuk model transformasi pengalaman, yaitu pengamatan reflektif (observation reflection) dan pengalaman aktif (active experience). Tahapan - tahapan model pembelajaran experiential learning merupakan sebuah lingkaran sebagai berikut: 


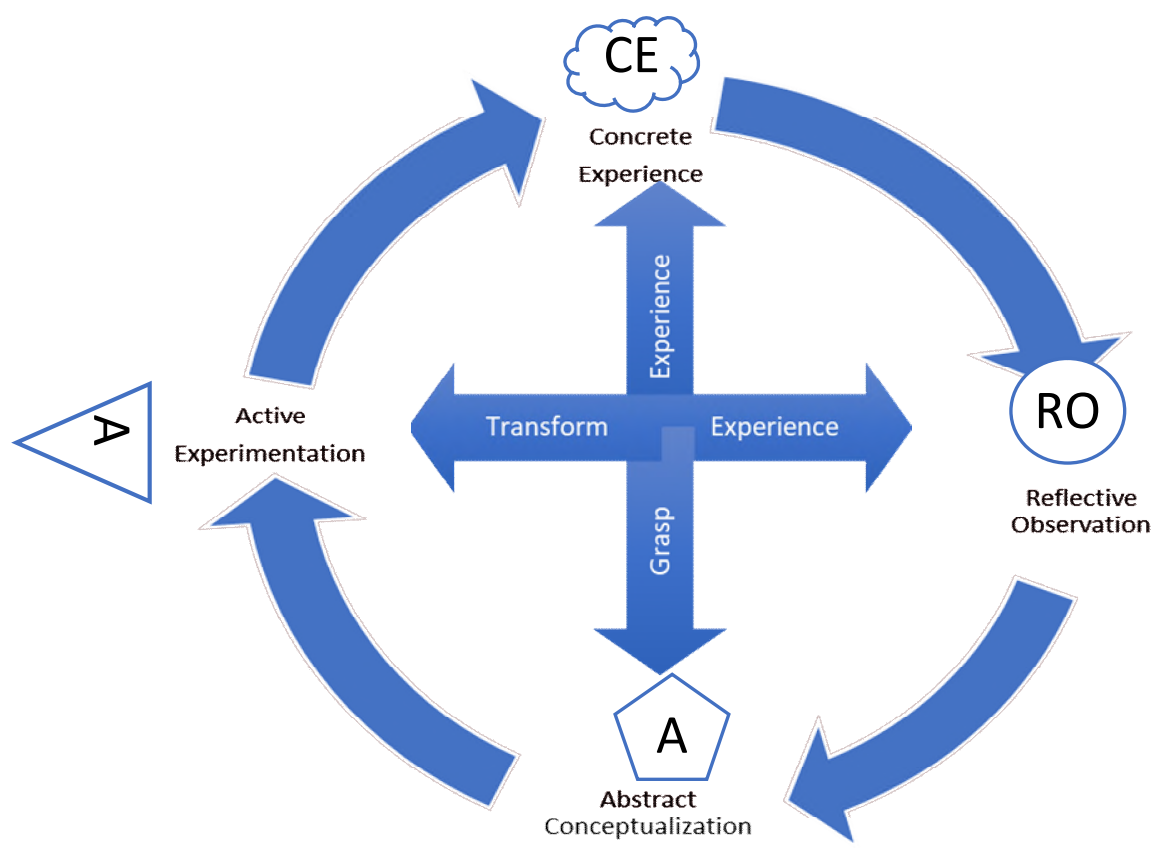

Bagan siklus model Experiential Learning (Kolb, 2014:51)

Berdasarkan paparan di atas, maka tujuan penelitian ini adalah untuk mendeskripsikan upaya pengembangan karakter anak melalui model pembelajaran Experiential Learning di Homy School Palangka Raya Kalimantan Tengah.

\section{METODE PENELITIAN}

Penelitian ini merupakan penelitian deskriptif dengan pendekatan kualitatif dengan tujuan untuk untuk mendeskripsikan upaya pengembangan karakter anak melalui model pembelajaran Experiential Learning di Homy School Palangka Raya Kalimantan Tengah. Subjek dari penelitian ini yaitu pendidik (tutor), anak dan kepala sekolah (PIC). Teknik yang digunakan untuk menganalisis data menggunakan teknik deskriptif kualitatif. Peneliti menggunakan pendekatan kualitatif karena permasalahan yang dibahas lebih banyak mendeskripsikan, menguraikan dan menggambarkan tentang upaya pengembangan karakter anak melalui model Experiential Learning di sekolah tersebut.

Pengumpulan data dalam penelitian ini menggunakan beberapa metode, antara lain: Observasi partisipatif; wawancara informal melalui percakapan atau tanya jawab dan juga menggunakan alat rekam disamping mencatat hasil percakapan; dokumentasi Jurnal Pendidikan Dan Psikologi Pintar Harati Vol. 15 No. 2, Desember 2019 
(catatan harian, (Learning Journal anak), foto, gambar, hasil karya anak, serta dokumen lain yang mendukung informasi penelitian)

Analisa data pada penelitian ini menggunakan teknik analisis deskriptif kualitatif. Analisis dibagi menjadi 3 tahapan (Miles \& Huberman, dalam Sugiyono 2008:337), yaitu: Reduksi Data (Data Reduction), Penyajian Data (Data Display), Penarikan Kesimpulan (Conclusion Drawing/verification).

\section{HASIL DAN PEMBAHASAN}

Berdasarkan hasil observasi mulai 14 Januari 2019 - 30 Mei 2019, dan juga wawancara kepada seluruh tutor diperoleh hasil bahwa semua tutor per tingkatan kelas selalu membuat Lesson Plan sebelum melaksanakan pembelajaran. Namun demikian, sebagian besar tutor tidak memasukkan pendidikan karakter secara eksplisit atau langsung ke dalam lesson plan pembelajaran namun terintegrasi dalam kegiatan devotion (kebaktian rutin sebelum memulai kegiatan bagi yang Nasrani, yang bukan Nasrani dipersilahkan untuk datang setelah jam devotion atau boleh memilih kegiatan lain). Selain itu, dalam rutinitas harian dimulai sejak anak datang ke sekolah mereka saling mengucapkan salam, bermain bersama, snack time bergilir, piket, quiet time (storytelling), makan siang bersama. Pengembangan karakter terjadi secara alami atau natural dalam keseharian anak di sekolah.

Selain itu, diketahui pula bahwa di Homy School Palangka Raya menerapkan empat tahapan pembelajaran experiential learning dalam upaya pengembangan karakter anak, yakni:

1. Pengalaman Konkrit

Beberapa poin misi dari Homy School adalah menumbuhkan kasih dan toleransi terhadap sesama melalui pendidikan multikultural dan memfasilitasi anak berkebutuhan khusus (Additional Support Needs Children). Dengan bergabungnya berbagai macam anak dari latar belakang berbeda (suku, budaya, agama, status ekonomi dan anak berkebutuhan khusus). Disini sebenarnya anakanak tanpa sadar mengalami pembelajaran langsung dimana anak melihat bahwa di dunia ini terdapat banyak teman yang warna rambut, mata dan kulitnya berbeda satu sama lain (ada anak Amerika, keturunan Inggris, Spanyol, Italia, Tionghua, Jawa, Dayak, Batak, Banjar, dan suku lainnya). Ada anak yang 
memerlukan shadow teacher (anak sindroma autistik dan ADHD). Ada pula anak yang memakai alat bantu dengar (tuna runggu). Salah satu contoh, ketika anak tuna runggu usia 8 tahun bergabung di Homy School, anak-anak lainnya begitu tertarik melihat dan menceritakan dengan tutor maupun orang tua mengenai teman barunya tersebut.

2. Observasi Refleksi

Pada tahap ini, kembali pada contoh anak tuna runggu yang bergabung di Homy School, anak-anak mulai bertanya baik kepada tutor maupun orang tua mengenai temannya tersebut. Pertanyaan seperti mengapa temannya tersebut memakai alat bantu dengar, mengapa temannya tersebut tidak bisa mendengar tanpa alat bantu tersebut, mengapa ketika beraktivitas yang terlalu banyak gerak alat bantu dengar harus dilepaskan, dan mengapa bicaranya belum terlalu jelas.

3. Berpikir Abstrak

Masih contoh mengenai teman yang tuna runggu, pada tahap ini anak-anak sudah mencoba membuat suatu konsep bahwa temannya tersebut menggunakan alat bantu dengar agar dapat mendengar pembicaraan dan suara dari lingkungannya meskipun tidak terlalu jelas juga karena anak-anak atau tutor masih harus berbicara dengan volume agak tinggi. Selain itu, anak juga mulai menghubungkan bahwa temannya tersebut belum terlalu lancar bicara dikarenakan ia telat mendengar suara dari lingkungannya.

4. Pengalaman Aktif atau Penerapan

Pada tahap ini, ada anak yang secara aktif mengajak temannya yang tuna runggu tersebut bermain bersama dengan mencoba berkomunikasi langsung ada yang mencoba berkomunikasi sambil menggunakan Bahasa tubuh maupun bahasa isyarat seperti menepuk bahu, mencolek bahu, menggandeng tangan, kode untuk mengajak makan, minum, ataupun menyemangati dengan mengepalkan tangan sambil mengatakan semangat.

Secara keseluruhan hasil dari penelitian ini menunjukkan bahwa pelaksanaan model pembelajaran Experiential Learning di Homy School Palangka Raya dapat mengembangkan karakter anak.Dalam kegiatan belajar mengajar, sehari-hari di Homy School Palangka Raya, Kalimantan Tengah seluruh anak mulai dari usia 18 bulan - 3 
tahun (toddler), 3 tahun - 5 tahun (preschool), 6 - 12 tahun (primary) ada kesempatan bermain bersama (free play) di pagi hari. Kegiatan pembelajaran di Homy School Palangka Raya baru akan dipisah setelah devotion time. Di Homy School Palangka Raya, setiap anak memiliki kemerdekaan memilih belajar dan mengembangkan potensinya dengan senang dan riang tanpa paksaan, tanpa ancaman, tanpa kekerasan, tanpa harus dibanding-bandingkan satu sama lain. Salah satu misi Homy School Palangka Raya adalah mendidik anak menjadi pembelajar sejati (lifelong learner) yang berintegritas, tangguh, mandiri, aktif, dan kreatif, melalui proses pembelajaran yang Holistik-Integratif, kreatif, inovatif, inspiratif, ramah anak, dan penuh kasih. Hal tersebut sejalan dengan tujuan pendidikan karakter menurut Herritage Foundation yakni membentuk manusia secara utuh (holistik) yang berkarakter, yaitu mengembangkan aspek fisik, emosi, sosial, kreativitas, spiritual dan intelektual anak secara optimal. Selain itu juga membentuk manusia pembelajar sejati (lifelong learners) (Musfiroh dalam Arismantoro, 2008).

Terkait upaya pengembangan karakter anak, model pembelajaran yang diterapkan di Homy School Palangka Raya yakni Experiential Learning juga sejalan dengan pendapat Kilpatrick (dalam Arismantoro, 2018:30), yakni "karakter anak dikembangkan melalui tahap pengetahuan, tindakan menuju kebiasaan". Experiential Learning secara harfiah berarti belajar dari aktifitas mengalami dan merefleksikan apa yang telah dipelajari. Experiential bukan sekedar mendengarkan tetapi lebih pada mensimulasikan situasi kehidupan nyata, misalnya field trip, bermain peran, dan berpartisipasi dalam permainan. Dalam experiential learning melibatkan tubuh, pikiran, perasaan, dan tindakan. Oleh karena itu merupakan pengalaman belajar pribadi yang utuh (Kolb, 2014).

Di Homy School Palangka Raya, pendidikan karakter tidak secara eksplisit atau langsung masuk dalam lesson plan pembelajaran namun terintegrasi dalam kegiatan devotion (kebaktian rutin sebelum memulai kegiatan bagi yang Nasrani, yang bukan Nasrani dipersilahkan untuk datang setelah jam devotion atau boleh memilih kegiatan lain). Disini anak belajar untuk toleransi yakni menghormati teman yang berbeda agama. Selain itu, dalam rutinitas harian dimulai sejak anak datang ke sekolah mereka saling mengucapkan salam dan mengisi "cup of their feeling" (anak belajar peduli dengan diri dan lingkungannya) dan bermain bersama (anak mengembangkan toleransi, 
empati dan cinta kasih dimana anak primary bermain bersama dengan anak preschool dan toddler). Ada juga snack time dan piket bergilir (disini anak berlatih untuk bertanggung jawab dan mandiri). Selanjutnya kegiatan rutin lainnya adalah quiet time (storytelling) disini anak dapat pengetahuan mengenai karakter positif melalui cerita moral. Akhir dari rutinitas harian anak adalah makan siang bersama, disini anak belajar untuk mandiri dan bertanggung jawab seperti merapikan dan mencuci alat makannya sendiri. Pengembangan karakter terjadi secara alami atau natural dalam keseharian anak di sekolah yang akhirnya anak menjadi terbiasa (kebiasaan).

Menurut David Kolb (2014: 32), Experiential Learning step are 1) concrete experience, 2) observation and reflections, 3) formations of abstract concept and generalizations, and 4) testing implementations. Empat tahapan pembelajaran experiential learning dalam upaya pengembangan karakter anak, yakni:

1. Pengalaman Konkret

Beberapa poin misi dari Homy School adalah menumbuhkan kasih dan toleransi terhadap sesama melalui pendidikan multikultural dan memfasilitasi anak berkebutuhan khusus (Additional Support Needs Children). Dengan bergabungnya berbagai macam anak dari latar belakang berbeda (suku, budaya, agama, status ekonomi dan anak berkebutuhan khusus). Disini sebenarnya anakanak tanpa sadar mengalami pembelajaran langsung dimana anak melihat bahwa terdapat banyak teman yang warna rambut, mata dan kulitnya berbeda satu sama lain (ada anak Amerika, keturunan Inggris, Spanyol, Italia, Tionghua, Jawa, Dayak, Batak, Banjar, dan suku lainnya). Ada anak yang memerlukan shadow teacher (anak sindroma autistik dan ADHD). Anak-anak dalam kesehariannya belajar untuk bertoleransi, memiliki cinta kasih, dan empati.

Ada pula anak yang memakai alat bantu dengar (tuna runggu).

Salah satu contoh, ketika anak tuna runggu usia 8 tahun bergabung di Homy School, anak-anak lainnya begitu tertarik melihat dan menceritakan dengan tutor maupun orang tua mengenai teman barunya tersebut. Anak bercerita kepada tutor dan orang tua merupakan hal yang sangat biasa. Homy School Palangka Raya menerapkan pendidikan berbasis keluarga dan komunitas dimana tutor dan orang tua berkolaborasi dalam tumbuh kembang anak. Hal tersebut sejalan dengan pernyataan bahwa "Masyarakat membentuk karakter melalui pendidik 
dan orang tua agar anak bersedia bertingkah laku seperti yang dikehendaki masyarakat" (Alwisol dalam Arismantoro, 2008)

2. Observasi Refleksi

Pada tahap ini, kembali pada contoh anak tuna runggu yang bergabung di Homy School, anak-anak mulai bertanya baik kepada tutor maupun orang tua mengenai temannya tersebut. Pertanyaan seperti mengapa temannya tersebut memakai alat bantu dengar, mengapa temannya tersebut tidak bisa mendengar tanpa alat bantu tersebut, mengapa ketika beraktivitas yang terlalu banyak gerak alat bantu dengar harus dilepaskan, dan mengapa bicaranya belum terlalu jelas. Disini anak-anak belajar untuk peduli dengan lingkungannya (dalam hal ini temannya).

3. Berpikir Abstrak

Masih contoh mengenai teman yang tuna runggu, pada tahap ini anak-anak sudah mencoba membuat suatu konsep bahwa temannya tersebut menggunakan alat bantu dengar agar dapat mendengar pembicaraan dan suara dari lingkungannya meskipun tidak terlalu jelas juga karena anak-anak atau tutor masih harus berbicara dengan volume agak tinggi. Selain itu, anak juga mulai menghubungkan bahwa temannya tersebut belum terlalu lancar bicara dikarenakan ia telat mendengar suara lingkungannya. Disini anak juga belajar konsep menghargai dirinya sendiri, teman serta lingkungannya. Anak yang normal bersyukur kepada Tuhan (meningkatkan spiritual anak), anak yang berkebutuhan khusus bersyukur karena merasa diterima oleh lingkungannya.

4. Pengalaman Aktif atau Penerapan

Pada tahap ini, ada anak yang secara aktif mengajak temannya yang tuna runggu tersebut bermain bersama dengan mencoba berkomunikasi langsung ada yang mencoba berkomunikasi sambil menggunakan bahasa tubuh maupun bahasa isyarat seperti menepuk bahu, mencolek bahu, menggandeng tangan, kode untuk mengajak makan, minum, ataupun menyemangati dengan menggepalkan tangan sambil mengatakan semangat. Disini anak-anak berlatih untuk menjadi pribadi yang kreatif, aktif, dan percaya diri. Pengalaman aktif berarti kemampuan untuk melaksanakan berbagai hal dengan orang-orang dan melakukan tindakan berdasarkan peristiwa termasuk pengambilan resiko. Disini anak-anak secara tidak langsung belajar untuk jujur (bisa saja kalau anak yang memiliki karakter 
buruk akan mengejek temannya yang berkebutuhan khusus tersebut atau membohongi temannya tersebut namun kenyataannya tidak demikian). Pengalaman aktif merupakan belajar melalui tindakan, menekankan pada aplikasi praktis dalam konteks kehidupan nyata. Teknik instruksional yang digunakan antara lain field work, laboratory work, games, drama, dan simulasi (Kolb, 2014). Salah satu kegiatan rutin yang dilakukan adalah outbound dimana melalui kegiatan ini anak berlatih untuk mandiri, bertanggungjawab, dan gemar belajar.

\section{KESIMPULAN}

Berdasarkan hasil penelitian dan pembahasan tentang upaya pengembangan karakter anak melalui model pembelajaran Experiential Learning di Homy School Palangka Raya Kalimantan Tengah dapat disimpulkan secara umum bahwa anak-anak mengembangkan karakter positif seperti anak menjadi lebih peduli dan menghargai dirinya sendiri, teman serta lingkungannya, religius, toleransi, jujur, memiliki rasa cinta kasih, empati, mandiri, bertanggungjawab, kreatif, aktif, percaya diri, dan gemar belajar. Keseluruhannya tersebut terwujud melalui model pembelajaran experiential learning dimana karakter anak dikembangkan melalui tahap pengetahuan, tindakan menuju kebiasaan. Anak- anak mengalami upaya pengembangan karakter tersebut secara langsung dalam kesehariannya dimana prosesnya terjadi terus menerus disertai kolaborasi antara anak dengan lingkungannya (tutor, orang tua, maupun lingkungan sekitar anak).

Dalam upaya pengembangan karakter anak melalui model pembelajaran Experiential Learning di Homy School Palangka Raya Kalimantan Tengah, disarankan agar terus terjaga konsistensi dan kolaborasi yang baik antara pihak sekolah (tutor) dan orang tua. Selain itu, diharapkan tidak melupakan evaluasi rutin dalam setiap kegiatan yang dilakukan. 


\section{DAFTAR PUSTAKA}

Arismantoro. (2008). Character Building: Bagaimana Mendidik Anak Berkarakter. Yogyakarta: Tiara Wacana.

Kolb, David A. (2014). Experiential Learning: Experience As The Source of Learning and Development $2^{\text {nd }}$. New Jersey: Pearson FT Press.

Ratnaya, I. G., (2011). Dampak Negatif Perkembangan Teknologi Informatika Dan Komunikasi Dan Cara Antisifasinya. JPTK, UNDIKSHA, Vol. 8, No. 1, Januari $2011: 17-28$. Diunduh dari https://www.researchgate.net/publication/315593183_DAMPAK_NEGATIF_P ERKEMBANGAN_TEKNOLOGI_INFORMATIKA_DAN_KOMUNIKASI_D AN_CARA_ANTISIFASINYA/link/5aca5be70f7e9bcd5198ae42/download, diakses tanggal 18 Juli 2019.

Sugiyono. (2008). Metode Penelitian Pendidikan Pendekatan Kuantitatif, Kualitatif dan $R \& D$. Bandung: Penerbit Cv. Alfabeta.

Sukadini, Rini. (2019). Peran Pendidikan Karakter Kristen Di Era Revolusi Industri 4.0. (Https://Www.Skketapang.Org/Peran-Pendidikan-Karakter-Kristen-Di-EraRevolusi-Industri-4-0/), diakses 16 Juli 2019.

Wikipedia. (2019). Karakter. (https://id.wikipedia.org/wiki/Karakter), diakses 18 Juli 2019. 